\title{
Convection Streams and Macrosegregation Couple Phenomena for Dendritic Solidification Defects in Casting Processes
}

\author{
M. O. El-Bealy ${ }^{1,2}$ \\ ${ }^{1}$ Companies' Chair of Materials Processing \& Technology, ASU, Egypt, CTU, Germany, KTH, Sweden and MIT, \\ USA \\ ${ }^{2}$ Sweden Branch: Royal Institute of Technology, Institute of Materials Processing, S-100 44 Stockholm, Sweden \\ Correspondence: M. O. El-Bealy, 91 Abd Aziz Fahmy St. \# 36 Heliopolis, 11361, Cairo, Egypt. Tel: \\ 202-26-323-366. E-mail: moelbealy@hotmail.com
}

Received: January 14, 2013 Accepted: March 12, 2013 Online Published: April 15, 2013

doi:10.5539/jmsr.v2n3p1 URL: http://dx.doi.org/10.5539/jmsr.v2n3p1

\begin{tabular}{|c|c|c|}
\hline \multicolumn{3}{|c|}{ Nomenclature } \\
\hline$a$ & coefficient in Table IV & \\
\hline$A$ & phase fraction & \\
\hline$C$ & concentration of $\mathrm{Cu}$ & $(w t \%)$ \\
\hline$C_{d A}$ & generalized drag coefficient & \\
\hline$d_{s}$ & grain diameter & $(\mu \mathrm{m})$ \\
\hline$D$ & diffusion coefficient & $\left(\mathrm{m}^{2} / \mathrm{s}\right)$ \\
\hline $\mathrm{E}$ & coefficient in Table IV & \\
\hline$g$ & gravitational acceleration & $\left(\mathrm{m} / \mathrm{s}^{2}\right)$ \\
\hline$H$ & enthalpy & $(\mathrm{J} / \mathrm{kg})$ \\
\hline$k$ & thermal conductivity & $(\mathrm{W} / \mathrm{mK})$ \\
\hline $\mathbf{k}$ & unit vector in $\mathrm{z}$ direction & \\
\hline$J_{0}$ & nominal concentration & $(\mathrm{wt} \%)$ \\
\hline$l$ & diffusion length & $(\mathrm{m})$ \\
\hline$L$ & length of total test line & $(\mathrm{m})$ \\
\hline$M$ & Magnification & \\
\hline$M_{s}^{d}$ & interfacial drag & $\left(\mathrm{N} / \mathrm{m}^{3}\right)$ \\
\hline$n$ & grain density & $\left(1 / \mathrm{m}^{3}\right)$ \\
\hline$n_{l}$ & lineal density of the grains & (intercepts/mm) \\
\hline$n_{i}$ & the number of intercepts counted per field & (intercepts) \\
\hline$P$ & pressure & $\left(\mathrm{N} / \mathrm{m}^{2}\right)$ \\
\hline$R_{s}$ & grain radius & $\left(1 / \mathrm{m}^{2}\right)$ \\
\hline $\operatorname{Re}$ & multiphase Reynolds number & \\
\hline Sc & Schmidt number & \\
\hline Sv & interfacial area concentration & $(1 / \mathrm{m})$ \\
\hline$t$ & time & $(\mathrm{s})$ \\
\hline$T$ & temperature & $\left({ }^{\circ} \mathrm{C}\right)$ \\
\hline $\mathbf{v}$ & velocity vector & $(\mathrm{m} / \mathrm{s})$ \\
\hline$x, z$ & Cartesian coordinate & \\
\hline
\end{tabular}




\begin{tabular}{|c|c|c|}
\hline \multicolumn{3}{|c|}{ Greek Symbols } \\
\hline$\delta$ & impingement function in Equation (T-4-2) & \\
\hline$\Delta H$ & latent heat of fusion & $(\mathrm{J} / \mathrm{kg})$ \\
\hline$\Gamma$ & interfacial mass-transfer rate due to phase change & $\left(\mathrm{kg} / \mathrm{m}^{3} \mathrm{~s}\right)$ \\
\hline$\kappa$ & partition coefficient & \\
\hline$\mu$ & dynamic viscosity & $(\mathrm{kg} / \mathrm{s} \mathrm{m})$ \\
\hline$v$ & kinematic viscosity & $\left(\mathrm{m}^{2} / \mathrm{s}\right)$ \\
\hline$\rho$ & density & $\left(\mathrm{kg} / \mathrm{m}^{3}\right)$ \\
\hline \multicolumn{3}{|c|}{ Subscripts } \\
\hline$e$ & eutectic & \\
\hline$i$ & interfacial & \\
\hline$k$ & phase & \\
\hline$l$ & liquid & \\
\hline$m$ & pure solvent & \\
\hline$o$ & initial & \\
\hline$p$ & primary & \\
\hline$s$ & solid & \\
\hline \multicolumn{3}{|c|}{ Superscripts } \\
\hline- & Interfacial & \\
\hline$t$ & transpose & \\
\hline
\end{tabular}

\begin{abstract}
An investigation has been performed to study the effects of convection streams and the movement of dendritic solid on the macrosegregation in equiaxed structure of aluminium cast ingots. The investigation combined laboratory work, metallographic examination and mathematical modelling. The laboratory work involved different superheats for $\mathrm{Al}-10 \% \mathrm{Si}$ alloy cast ingots. The measurements of grain size of equiaxed crystals and macro-segregation distributions have been conducted to verify the solidification model by using the metallographic study combined macro/micro-structural evolution of cast ingot samples. Two-dimensional mathematical model of fluid flow and heat transfer has been developed to characterise the natural convection streams, thermal fields and macro-segregation distributions taken into account the effect of dendritic solid movements. The model predictions were compared to measurements of cooling curves and macro-segregation distributions where the reasonable agreements were found. The formation of macro-segregation phenomenon has been studied and discussed based on convection streams, the movements of dendritic solid and mushy permeability. Also, some typical cases in conventional casting processes related to increase the occurrence of dendritic solidification defects have been discussed.
\end{abstract}

Keywords: macrosegregation, heat flow, mushy permeability, convection streams, dendritic equiaxed structure

\title{
1. Introduction
}

Casting of precision product, such as those used in modern defence systems is a complex process. The casting engineer is faced with the daunting task of selecting an optimum combination of multitude of process and design parameters to ensure a defect free cast part with desired microstructure. Dendritic solidification defects like high segregation, interdendritic cracks and others often result in high scrap rate or other costs. However, computer simulation of the casting processes in the recent years has begun to help the casting engineers in the cost and quality effective selection of design and process parameters. Most casting simulations codes up to date contain modules for heat transfer (Sully, 1976; Ho \& Pehlke, 1985; Bamberger et al., 1987; Shah \& Moore, 1989), fluid flow (Muller et al., 1984; Nielsen et al., 1999; Griffiths, 1996) solidification (Poirier et al., 1991; De Groh III, 1994; El-Bealy \& Fredriksson, 1996; El-Bealy, 2000) and interdendritic strain analyses (Weiner \& Boley, 1963; Kristiansson, 1982; El-Bealy, 2011). These codes use individually in predicting and minimising of different solidification defects and also in predicting of cast microstructure. The mathematical models for these codes 
focus on the effect of cooling conditions and convection patterns on the solidification process. Subsequently, the couple effect of different types of convection streams and mushy permeability on the movement of solid, segregation level and hence on the interdendritic defects formation during dendritic solidification especially in dendritic equiaxed structure was ignored.

Therefore, the simulation of coupled liquid and solid flows is an important matter in dendritic equiaxed solidification processes but unfortunately it is little understood phenomenon. Convection in the liquid melt and in the interdendritic liquid is caused by both thermal and solutal buoyancy forces. The movement of free solid crystals is due to the influence of gravity and the superheat in liquid zone. However, in the mushy zone, the resulting solid-liquid multiphase flow pattern strongly depends on the micro-structure of the equiaxed crystals which, in turn, is governed by grain nucleation and growth mechanisms (Wang \& Beckermann, 1996). In the recent past, the thermo-solutal convection streams in the liquid melt or in interdendritic liquid in the columnar dendritic solidification which results in macro-segregation have been extensively studied. Unfortunately, the modelling of the convection streams in equiaxed structure has not been widely attempted. This is because of the complications associated with the transport of free solid crystals in the melt liquid zone or the movement and growth of equiaxed crystals in interdendritic liquid in the mushy zone. In the liquid zone, the gravity induced settling or flotation of free crystals based on the densities of alloying elements whereas the type of alloy system is fundamental to the nucleation and growth processes of equiaxed crystals in the mushy zone. Also, the initial nucleation of the equiaxed zone greatly affects the starting of columnar to equiaxed transition (Wang et al., 1995). Moreover, crystals transportation in the mushy zone may cause a severe macro-segregation and structural inhomogeneities (DeHoff \& Rhines, 1968; ASTM, 1987; El-Bealy, 1990, 2013; El-Bealy \& El-Emairy, 2007; El-Bealy \& Hammouda, 2007).

Therefore, this study describes an attempt towards predicting the effects of different melt superheats on the natural convection streams. Thus, the effect of these convection streams on the movement of silicon crystals and therefore on the macrosegregation of silicon. In section 2, it devoted an explanation of experimental work and its details whereas section 3 describes a 2-D model developed based on $\mathrm{Ni}$ and Beckermann approach (Ni \& Beckermann, 1991, 1993) where the segregation solute governing equation was derived based on multiphase approach. In the section 4, comparisons and exiting natural convection streams and segregation of silicon in the dendritic equiaxed structure were explained and analysed on the light of predictions and experimental results. Finally, the importance of the effect of grain structure type and the solid movement on the fluid flow in the liquid and mushy zones and therefore, on the homogeneity distribution of alloying elements was discussed in the section 5. This discussion will help to develop accurate models of macro-segregation and to explain the formation mechanisms of dendritic solidification defects.

\section{Exprimental Methodology and Metallographic Study}

The industrial $\mathrm{Al}-10 \% \mathrm{Si}$ aluminium alloy was selected for the experimental work where this alloy is $\mathrm{Al}-10 \% \mathrm{Si}$ alloy system and its nominal composition can be found in Table 1. The selection of this alloy close to eutectic alloy $(\mathrm{Al}-12.6 \% \mathrm{Si})$ is to clarify the effect of convection streams on the movement of silicon crystals or solid phase during dendritic solidification.

Table 1. Chemical analysis of specimens

\begin{tabular}{cccccc}
\hline Alloy & $\mathrm{Si}$ & $\mathrm{Fe}$ & $\mathrm{Mn}$ & $\mathrm{Cu}$ & $\mathrm{Ti}$ \\
\hline $\mathrm{Al}-\mathrm{Si}$ & 10.2 & 0.23 & 0.006 & 0.07 & 0.012 \\
\hline
\end{tabular}

The experimental work has been done in the metallurgical laboratory in Design and Production Engineering Department in Ain Shams University in Cairo in Egypt. Subsequently, the experiments were conducted in horizontal induction furnace build in order to achieve a complete control of temperature distributions in the furnace. This maintains a high homogeneity of these distributions in the melt inside the mould. Also, it is to allow the crystals to grow parallel to steel mould chill and to solidify $80 \mathrm{~mm}$-length $\times 40 \mathrm{~mm}$-height $\times 20$ mm-thickness parallelepiped ingots. The basic setup of the experimental apparatus is illustrated in Figure 1. This mould is horizontal rectangular parallelepiped cavity cooled by water-chill. This mould is instrumented with thermocouples into the melt of aluminium alloys as shown in Figures 2(a, b). Six thermocouples (Ni-NiCr) were inserted into alloy melt. Three of these thermocouples in the upper side whereas the others were in the lower side as shown in Figures 2(a,b). Another thermocouple was inserted at steel chill at $2 \mathrm{~mm}$ from the chill surface as 
seen in Figures 2(a, b). Temperatures data from the thermocouples sent automatically into multi-channels digital thermometer.

Several experimental steps should be taken to prepare the master alloy before the experiments could be performed. The steps of preparation stage were explained in References (El-Bealy \& El-Emairy, 2007; El-Bealy \& Hammouda, 2007; El-Bealy, 2013) and the readers are referred to the original references for details of preparation stage of master alloy and the steps made in this stage. Then, the experiments were performed under the conditions summarised in Table 2 and the following experimental sequences were followed for each experiment;

1) putting the melting furnace at horizontal position and then fixing the steel mould inside it,

2) inserting the six thermocouples inside the ingot (thermocouples from number 1 to 6) and one thermocouple in the end chill wall (thermocouple number 7) as shown in Figure 2(a),

3) turn the furnace on and when the temperatures reach the predetermined desired superheat of the melt, the furnace was turned off and cooling system turned on,

4) while the thermocouples measured the temperatures at various locations in the chill and molten alloy. Then, the thermocouples sent these temperatures into the digital thermometer to record the temperature profiles,

5) when all thermocouples display a solidus temperature, the thermocouples were removed from the mould, then the steel mould removes from the furnace,

6) after several hours, the ingot was removed from the mould when its temperature reaches room temperature.

Then, the cast ingots were sectioned to two equal halves according to Figure 3(a). The specimens were prepared metallurgically for macro-microscopic examinations according to standard procedures in References (El-Bealy \& El-Emairy, 2007; El-Bealy \& Hammouda, 2007; El-Bealy, 2013). The macrographs exhibit a dendritic equiaxed structure as shown in Figure 3(b) with no difference in the morphology between the different experimental conditions illustrated in Table 2. The specimens then were micro-etched and were examined under a microscope. The micrographs were taken at magnifications of 200 at surface and subsurface ingot areas. The details of measured techniques of grain size by using the intercept method and macrosegregation analysis by measuring the volume fraction of second phase "Silicon" for Al-10\%Si alloy are illustrated in details in References (DeHoff \& Rhines, 1968; ASTM, 1987). The series of experimental work, examinations and measurements involved in this investigation are shown in Figure 4 as a flow chart.

Table 2. Summary of experiments for Macro/Micro-Examinations

\begin{tabular}{|c|c|c|c|c|c|}
\hline Exp. No. & Cooling condition & Alloy composition & $\begin{array}{c}\text { Superheat } \\
\left({ }^{\circ} \mathrm{C}\right)\end{array}$ & Chill material & $\begin{array}{l}\text { Specimen Height } \times \text { Width } \\
(\mathrm{mm})\end{array}$ \\
\hline E1 & Steady State & $\mathrm{Al}-10 \% \mathrm{Si}$ & 20 & steel & $40 \times 80$ \\
\hline E2 & Steady State & $\mathrm{Al}-10 \% \mathrm{Si}$ & 50 & steel & $40 \times 80$ \\
\hline E3 & Steady State & Al-10\%Si & 75 & steel & $40 \times 80$ \\
\hline
\end{tabular}

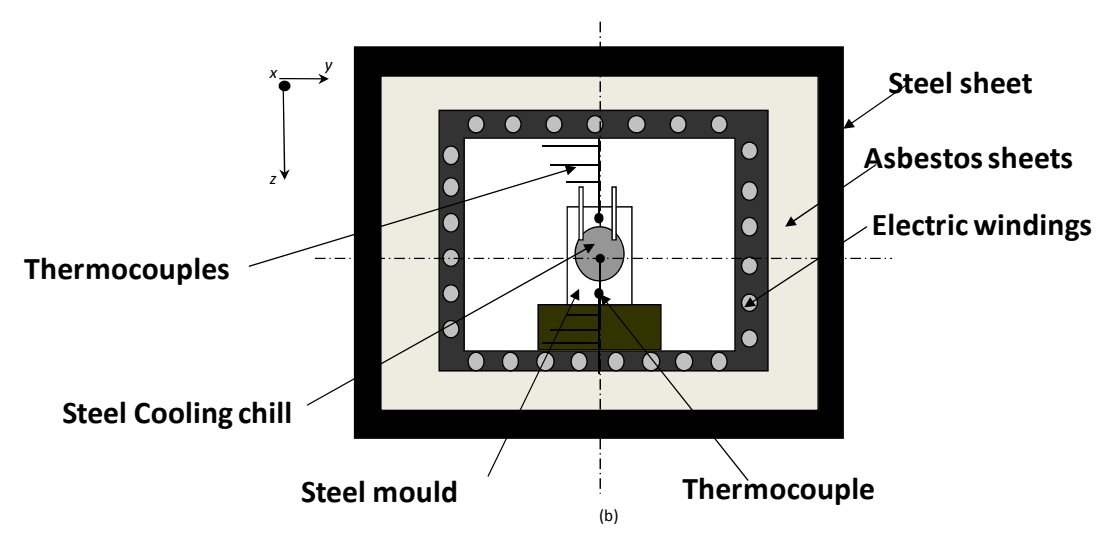

Figure 1. Schematic illustration of experimental apparatus 


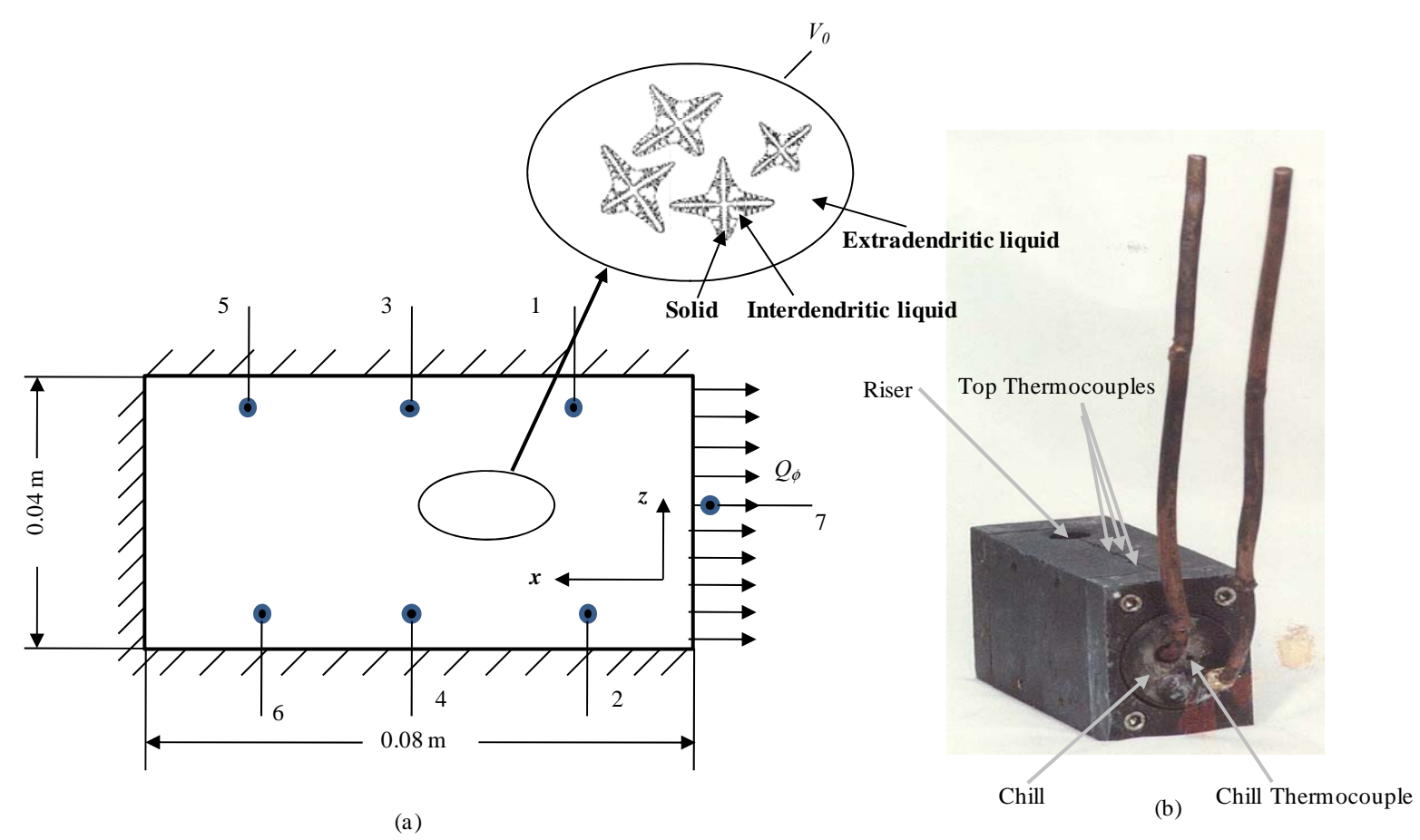

Figure 2. Schematic illustration of (a) physical system and (b) steel mould

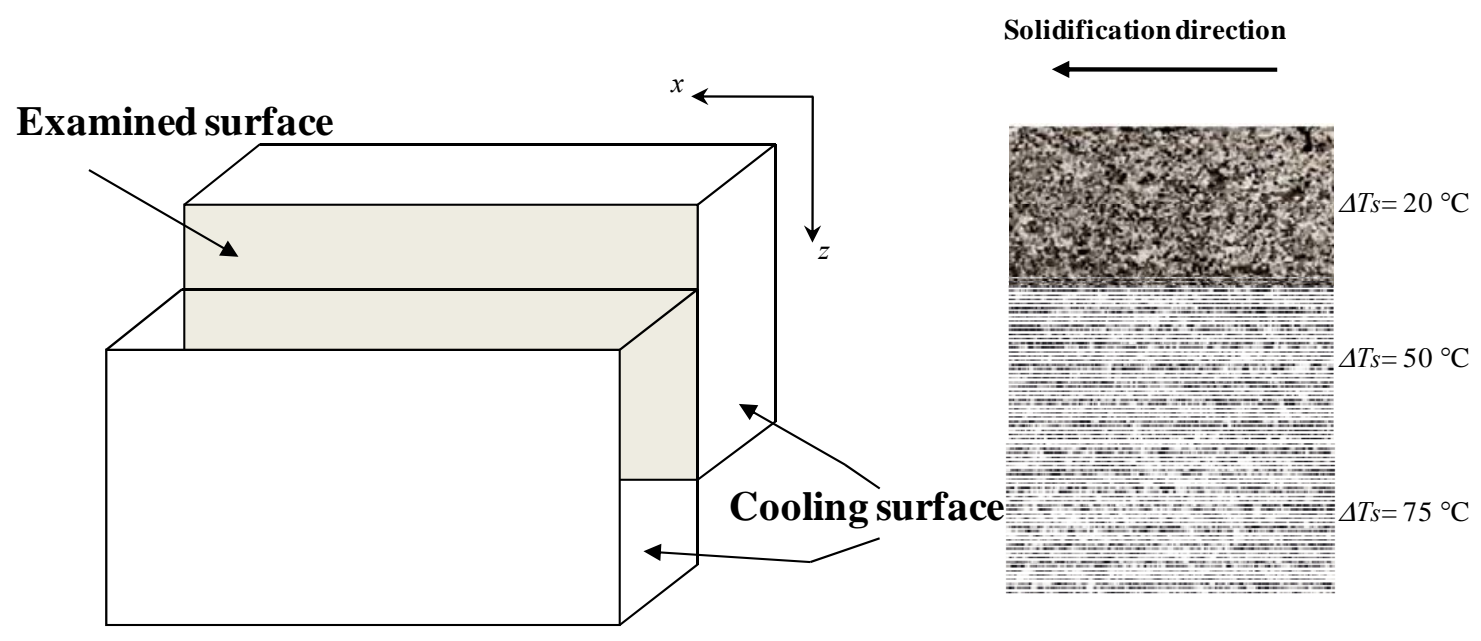

(a)

(b)

Figure 3. Schematic illustration of (a) longitudinal cross section and (b) macrographs 


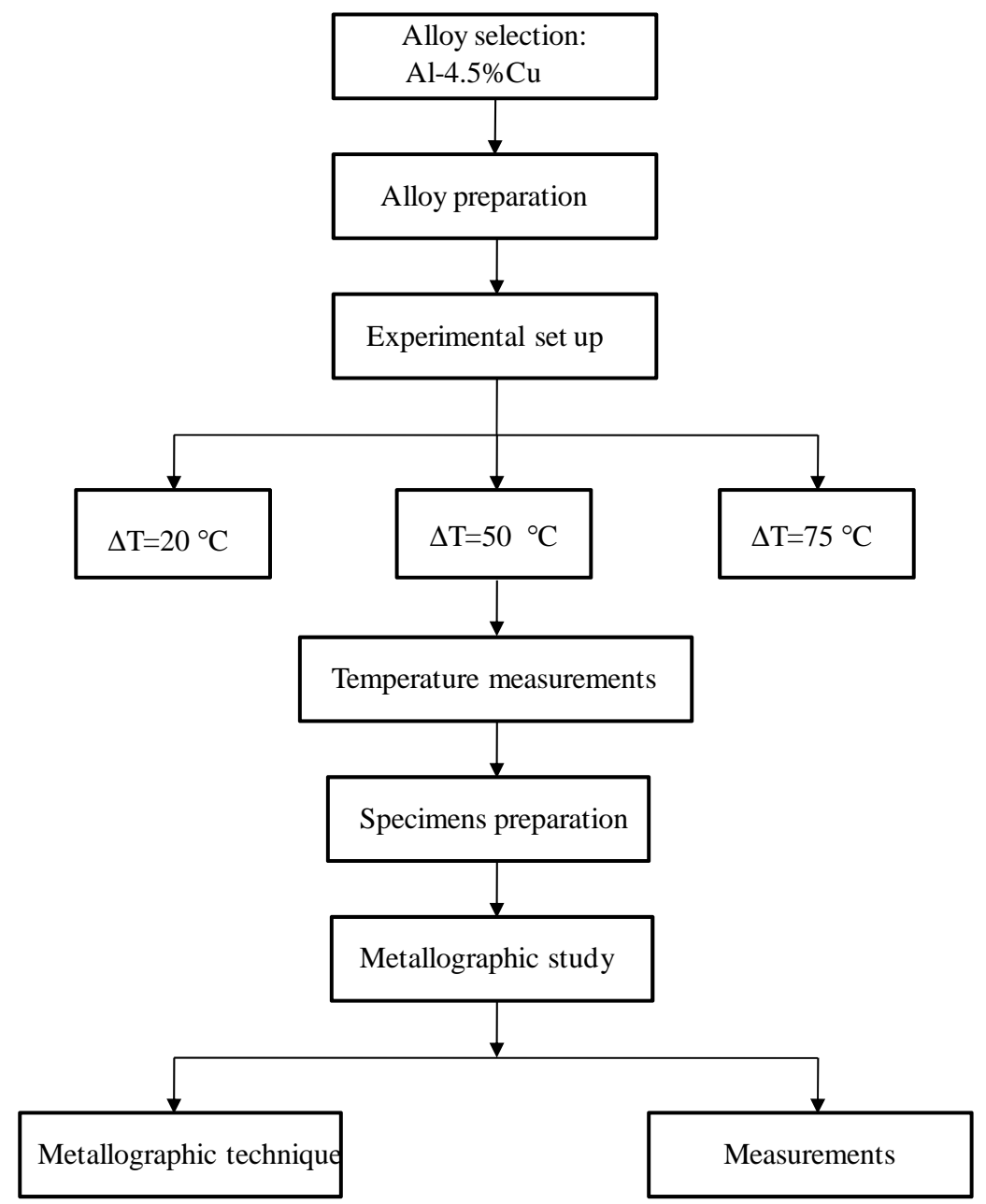

Figure 4. Flow chart of experimental work plane, examinations and measurements

\section{Model Description}

\subsection{Two-Phase Model}

A two-phase model used in the present simulations is a simplified version of the model developed in References (Ni \& Beckermann, 1991, 1993), and then extended in Reference (Wang \& Beckermann, 1996), to simulate the movement of equiaxed crystals. Tables 3 and 4 summarise the model governing equations and its supplementary relations, respectively. In the present study, only a few explanations are provided, and the readers are referred to the original references for the details of the model governing equations and the assumptions made in their derivations. Also, the symbols used in these equations are summarised in nomenclature in the beginning of this article.

The extension of two-phase model of the equaixed dendritic structure which has recently been presented in References (Ni \& Beckermann, 1991, 1993; Wang \& Beckermann, 1996) was used in the present paper. This multiphase approach considers a small control volume element. This element contains several equiaxed dendritic crystals, as schematically illustrated in Figure 2(a) in which two different interfacial length scales can be distinguished. Also, the element consists of the solid phase and two liquid phases. The two liquid phases separated by dendrite envelope are distinguished by their different interfacial length scales. Therefore, separate macroscopic conservation equations can then be formulated for each phase. In writing the energy in Equation (T-3-7), thermal equilibrium between the phases in an averaging volume has assumed, i.e. $T_{s}=T_{l}=T_{i}=T$, where $T_{i}$ is interfacial temperature. This appropriates due to the high value of Lewis number $(\alpha / D)$ for metal alloys. It is noted that species conservation equations illustrated in Equations (T-3-9) and (T-3-10), are solved for both the liquid and solid phases. The balance of interfacial species in Table 3 constitutes the microscopic grain growth model in the present set of equations. This states that the solute rejected upon solidification is either 
back-diffused in the solid or advected into under-cooled liquid. The two transport terms on the right-hand side of the interfacial species balance contain the interfacial area concentration shown in Table 4 Equation (T-4-2) and so-called diffusion lengths expressions for which are provided in Table 4 (Rowe et al., 1972; Agarwal, 1988). It has been shown elsewhere that the present back-diffusion model gives accurate predictions of solid micro-segregation and the final eutectic fraction. Keeping track of eutectic fraction is important for the prediction of contracting-driven flow as shown subsequently. The Kozeny-Carman relation for permeability of packed beds of spheres and the drag coefficient for a single sphere (stocks law) can be recovered from the interfacial drag correlation given in Eqsuation (T-4-1) and (T-4-4a), respectively, upon making the appropriate simplifications for the limiting cases (Geiger \& Poirier, 1973).

The number of grains per unit area $n$ is needed in the expression for interfacial area concentration and the grain radius is needed in the calculation of interfacial drag, (Agarwal, 1988) and spices diffusion length, (Rowe et al., 1972) see Equations (T-4-4a), (T-4-4a) and (T-4-5b), respectively. Although, a variable grain density was found to have a relatively small effect on the predicted macro-segregation (Reddy \& Beckermann, 1997) but in this study, the grain density is taken to be uniform for each control element and is equal to values as determined from the present experiments. The measured grain size is illustrated in Figures 5(a-c).

Table 4 provides the relation adopted for the liquid and solid densities as a function of temperature and concentration in Equations (T-4-6a) and (T-4-6b), respectively (Mangnusson \& Arnberg, 2001). Using liquid density relation in the buoyancy term in the momentum equation in Equations (T-3-5) and (T-3-6) implies that both thermal and solutal natural convection are taken into account. In the continuity equations, a fully variable liquid density, together with the primary and eutectic solid densities listed in Table 5, allow for the calculation of contraction-driven flow before and during solidification. The contraction behaviour of the present $\mathrm{Al}-10 \% \mathrm{Si}$ alloy during solidification is illustrated in References (Stangeland et al. 2004; Korojy, 2009). For simplicity, the Scheil equation is used to relate the liquid temperature/concentration to the solid fraction (Scheil, 1947). It can be seen that before the eutectic reaction, there is a range of solid fractions where the volume increases during solidification. Due to this expansion, the total contraction during primary solidification is only slightly positive. Therefore, much of the contraction-driven flow is caused by the drastic density change during the eutectic reaction.

\begin{tabular}{|c|c|c|c|c|c|}
\hline 711 & 546 & 500 & 492 & 473 & 467 \\
\hline 680 & 537 & 498 & 480 & 461 & 442 \\
\hline 668 & 508 & 485 & 471 & 452 & 421 \\
\hline 659 & 500 & 475 & 451 & 438 & 417 \\
\hline
\end{tabular}

(a) $\Delta \mathrm{T}=20 \mathrm{~K}$

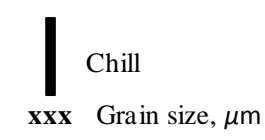

\begin{tabular}{|l|l|l|l|l|l|}
\hline 491 & 472 & 465 & 453 & 423 & 366 \\
\hline 476 & 441 & 455 & 410 & 378 & 365 \\
\hline 451 & 426 & 381 & 365 & 338 & 360 \\
\hline 439 & 380 & 378 & 347 & 325 & 302 \\
\hline
\end{tabular}

(b) $\Delta \mathrm{T}=50 \mathrm{~K}$

\begin{tabular}{|c|c|c|c|c|c|}
\hline 451 & 398 & 435 & 401 & 398 & 376 \\
\hline 415 & 379 & 385 & 374 & 357 & 350 \\
\hline 380 & 374 & 370 & 359 & 346 & 336 \\
\hline 372 & 354 & 345 & 336 & 318 & 309 \\
\hline
\end{tabular}

(c) $\Delta \mathrm{T}=75 \mathrm{~K}$

Figure 5. Variation of grain size in all control elements of longitudinal cross section with superheats (a) $20^{\circ} \mathrm{C}$, (b) $50{ }^{\circ} \mathrm{C}$ and (c) $75^{\circ} \mathrm{C}$ 


\subsection{System and Boundary Conditions}

A schematic of 2-D ingot casting shown in Figure 6(a) is very similar to the one employed in Reference (El-Bealy, 2013), for Al-4.5\%Cu alloy and simulated in the present study of $\mathrm{Al}-10 \% \mathrm{Si}$ alloy. The initial conditions when $t=0$, the pouring temperature $T_{\text {pour }}$ is assumed uniform throughout the ingot $T_{\varphi}=T_{p o u r}$ and the chemical species are also assumed to be consistently distributed and set to their initial values. Heat transfer between the ingot surface and mould wall was assumed to follow a generalised Newtonian law. Thus, it was assumed that heat flux across the ingot surface is proportional to the difference between ingot surface and water cooling constant temperatures as defined in References (El-Bealy, 1990, 2013; El-Bealy \& El-Emairy, 2007; El-Bealy \& Hammouda, 2007) and illustrated in Table 5. Therefore, the surface ingot heat flux at $\mathrm{x}=0$ can be computed as represented in References (El-Bealy, 1990, 2013; El-Bealy \& El-Emairy, 2007; El-Bealy \& Hammouda, 2007). For boundary conditions at $x=80, z=0, z=40 \mathrm{~mm}$, the heat fluxes can be calculated from the same equations in Reference (El-Bealy, 2013).

All system data and thermo-physical properties used in these simulations are summarised in Table 5 . As first approximation, all properties for each phase (expect the liquid density) are assumed constant and independent of temperature and concentration.
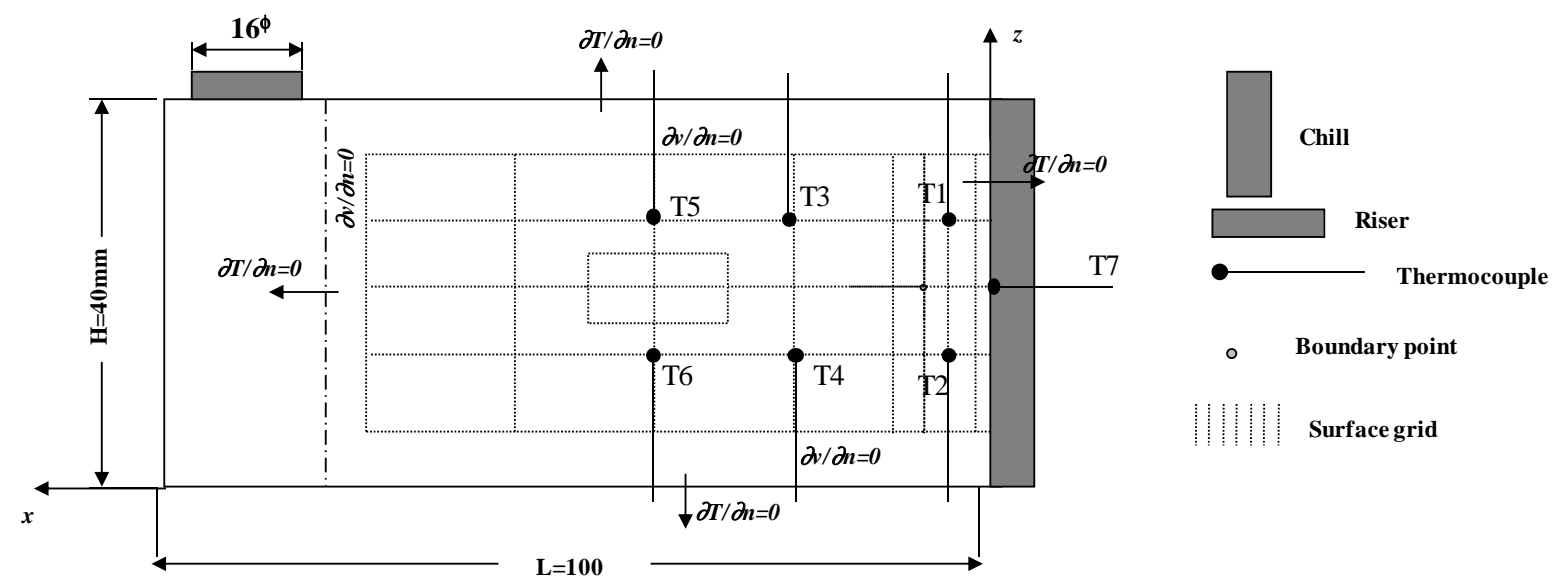

○ Boundary point

(a)

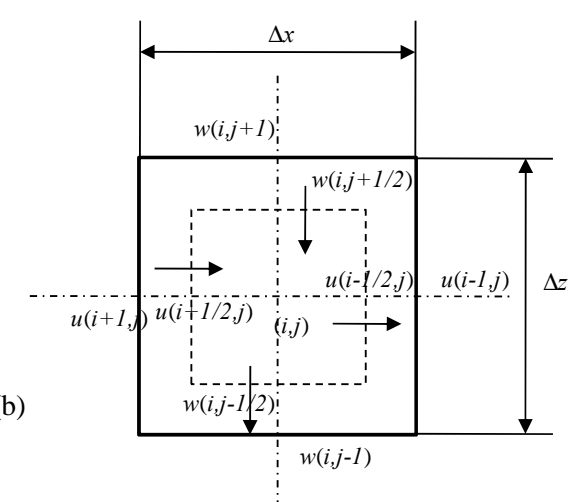

Figure 6. Schematic illustration of a) grid of computations and b) 2-D control volume of Simpler method 
Table 3. Summary of multiphase model

\section{- Continuity Equations:}

\section{Solid phase (s)}

$$
\frac{\partial}{\partial t}\left(A_{S} \rho_{S}\right)+\nabla .\left(A_{S} \rho_{S} v_{S}\right)=\Gamma_{S}
$$

Total liquid phase (l)

$$
\frac{\partial}{\partial t}\left(A_{l} \rho_{l}\right)+\nabla \cdot\left(A_{l} \rho_{l} v_{l}\right)=-\Gamma_{S}
$$

Interfacial mass balance

- Interfacial Species Balance

$$
\Gamma_{S}+\Gamma_{l}=0
$$

$$
\left(\overline{C_{e}}-\overline{C_{s d}}\right) \Gamma_{S}=\frac{\rho_{S} S_{S} D_{S}}{l_{s d}}\left(-\overline{C_{s d}}-C_{S}\right)+\frac{\rho_{l} S_{e} D_{l}}{l_{l d}}\left(\overline{C_{e}}-C_{l}\right)+\left[A_{d} \rho_{d} \frac{\partial \overline{C_{e}}}{\partial t}+A_{d} \rho_{d} v_{d} \cdot \nabla C_{e}-\bar{\nabla} \cdot\left(A_{d} \rho_{d} D_{d}^{*} \nabla \overline{C_{e}}\right)\right]
$$

- Momentum Equations

Solid phase (s)

$$
\frac{\partial}{\partial t}\left(A_{s} \rho_{s} v_{s}\right)+\nabla \cdot\left(A_{s} \rho_{s} v_{s} v_{s}\right)=-A_{s \nabla} p+\nabla \cdot\left(\mu_{s}^{*} A_{s} \nabla v_{s}\right)+M_{s}^{d}+A_{s} \rho_{s} g
$$

Total liquid phase (l)

$$
\frac{\partial}{\partial t}\left(A_{l} \rho_{l} v_{l}\right)+\nabla \cdot\left(A_{l} \rho_{l} v_{l} v_{l}\right)=-A_{l \nabla} p+\nabla \cdot\left(\mu_{l}^{*} A_{l} \nabla v_{l}\right)+M_{s}^{d}+A_{l} \rho_{l} g+\nabla \cdot\left[\gamma A_{l} \rho_{l}\left(v_{l}-v_{s}\right)\left(v_{l}-v_{s}\right)\right]
$$

- Mixture Energy Equation

$$
\frac{\partial}{\partial t}\left(A_{S} \rho_{S} H_{S}+A_{l} \rho_{l} H_{l}\right)+\nabla \cdot\left(A_{S} \rho_{s} v_{S} H_{S}+A_{l} \rho_{l} v_{l} H_{l}\right)=\nabla \cdot\left[\frac{k_{S} A_{S}}{c_{S}} \nabla H_{S}+\frac{k_{l} A_{l}}{c_{l}} \nabla H_{l}\right]
$$

where

$$
H_{s}=c_{p s} T, H_{l}=c_{p l} T+\left(c_{p s}-c_{p} ;\right) T_{e}+\Delta H
$$

- Species Equations

Solid phase (s)

$$
\frac{\partial}{\partial t}\left(A_{S} \rho_{S} C_{S}\right)+\nabla \cdot\left(A_{S} \rho_{S} v_{S} C_{S}\right)=\nabla \cdot\left(A_{S} \rho_{S} D_{S}^{*} \nabla C_{S}\right)+\bar{C}_{S} \Gamma_{S}+\frac{\rho_{S} S_{S} D_{S}}{l_{S d}}\left(\bar{C}_{S d}-C_{S}\right)
$$

Total liquid phase (l)

$$
\frac{\partial}{\partial t}\left(A_{l} \rho_{l} C_{l}\right)+\nabla .\left(A_{l} \rho_{l} v_{l} C_{l}\right)=\nabla \cdot\left(A_{l} \rho_{l} D_{l}^{*} \nabla C_{l}\right)+\left[-\bar{C}_{S d} \Gamma_{S}+\frac{\rho_{S} S_{S} D_{S}}{l_{s d}}\left(\bar{C}_{s d}-C_{S}\right)\right]+\nabla \cdot\left\{A_{l} \rho_{l}\left(v_{l}-v_{S}\right)\left[C_{l}-\kappa_{v} C_{d}-\left(1-\kappa_{v}\right) C_{l}\right]\right\}(
$$

Auxiliary Relations for Secondary Variables

Interdendritic liquid fraction

$$
\frac{\partial}{\partial t}\left(A_{l} \rho_{l}\right)+\nabla \cdot\left(A_{l} \rho_{l} v_{l}\right)=S_{e} \rho_{l}-\overline{w_{n e}}-\Gamma_{S}
$$

Extradendritic liquid fraction

Inter- and extradendritic liquid velocities

$$
A_{e}=A_{l}-A_{d}
$$

$$
\begin{aligned}
& v_{d}=v_{S}+\kappa_{v} \frac{A_{l} \rho_{l}}{A_{d} \rho_{l}}\left(v_{l}-v_{S}\right) \\
& v_{e}=v_{S}+\left(1+\kappa_{v}\right) \frac{A_{l} \rho_{l}}{A_{e} \rho_{e}}\left(v_{l}-v_{S}\right)
\end{aligned}
$$


Table 4. Interfacial and property relations

Mushy permeability;

$\underline{\text { Interfacial area concentration }}$

$$
\kappa=A_{l}^{3} / S_{A}^{2} k_{c}\left(1-A_{l}^{2}\right)
$$

$$
S_{A}=(36 \pi n)^{1 / 3} A_{s}^{2 / 3} \delta\left(A_{s}\right)
$$

where

$$
\begin{gathered}
\delta\left(A_{s}\right)=1 \text { for } A_{s} \leq A_{s p} ; \delta\left(A_{s}\right)=\left(\frac{A_{s}}{A_{s p}}\right)^{1 / 3}\left(\frac{1-A_{s}}{1-A_{s p}}\right)^{\frac{1-A_{s p}}{A_{s p}}} \text { for } A_{s} \succ A_{s p} ; \\
n_{l}=\frac{\overline{n_{i}}}{L / M} ; n=0.422 \times n_{l}
\end{gathered}
$$

Radius of the solid grains

$$
R_{s}=d_{s / 2}=\left[\frac{3 A_{s}}{4 \pi n}\right]^{1 / 3}
$$

Drag coefficient

$$
\begin{gathered}
C_{d A}=\left\{\frac{24 \times 2 C_{k A}\left(1-A_{i}\right)}{\operatorname{Re}}+C_{i A}\right\} ; \quad \operatorname{Re}=\frac{A_{i}\left|v_{i}-v_{s}\right| d_{s}}{v_{i}} \\
C_{k A}=25 / 6 ; \quad C_{i A}=7 / 3 ; \quad A_{i} \leq 0.5 \\
C_{k A}=\frac{1}{2} \frac{A_{i}^{3}}{1-A_{i}}\left[\frac{1+4.7\left(1-A_{l}\right)}{1-1.83\left(1-A_{l}\right)}\right] ; \quad C_{i A}=\frac{24\left(10^{E}-1\right)}{\operatorname{Re}\left[1-0.9\left(A_{i}-0.25\right)^{1 / 3}\left(1-A_{l}\right)^{2 / 3}\right]^{3}} ; A_{i} \succ 0.5
\end{gathered}
$$

where

$$
E=0.261 \mathrm{Re}^{0.369}-0.105 \mathrm{Re}^{0.431}-\frac{0.124}{1+\left(\log _{10} \mathrm{Re}\right)^{2}}
$$

Diffusion Lengths

$$
\begin{gathered}
l_{l}=\left[\frac{1}{\frac{1}{1-A_{s}^{1 / 3}}+\frac{1}{3 A_{l}} S c^{1 / 3} \mathrm{Re}^{a}} R_{s}^{;} \quad a=\frac{2 \mathrm{Re}^{0.28}+4.65}{3\left(\mathrm{Re}^{0.28}+4.65\right)}\right. \\
l_{s}=\frac{R_{s}}{5}
\end{gathered}
$$

Liquid density relation;

Solid density relation;

$$
\rho_{l}=2559.1-0.2820 T+3.371 C_{S i}
$$

Equilibrium phase diagram relations

$$
\rho_{s}=2688.6-0.1990 T-2.295 C_{s i}
$$

Primary solidification

$$
\bar{C}_{l i}=\frac{C_{e}\left(T_{m}-T\right)}{T_{m}-T_{e}} ; \quad \bar{C}_{s i}=\kappa \bar{C}_{l i}
$$

$\underline{\text { Eutectic solidification }}$

$$
T=T_{e} ; \quad C_{l i}=C_{e} \quad ; \quad \bar{C}_{s i}=C_{e}
$$


Table 5. Thermo-physical properties and system data

\begin{tabular}{ll}
\hline Properties & \\
\hline Density of primary solid phase, $\rho_{s p},\left(\mathrm{~kg} / \mathrm{m}^{3}\right)$ & 2390.1 \\
Density of eutectic solid phase, $\rho_{s e},\left(\mathrm{~kg} / \mathrm{m}^{3}\right)$ & 2397.5 \\
Dynamic viscosity of liquid phase, $\mu_{l},\left(\mathrm{~N} \mathrm{~s} / \mathrm{m}^{2}\right)$ & 0.0356 \\
Maximum solid packing fraction $A_{s p}$, & 0.700 \\
Thermal conductivity of the liquid phase, $k_{l},(\mathrm{~W} / \mathrm{m} \mathrm{K})$ & 57.76 \\
Thermal conductivity of the solid phase, $k_{s},(\mathrm{~W} / \mathrm{m} \mathrm{K})$ & 209.4 \\
Specific heat of liquid phase, $C_{p l},(\mathrm{~J} / \mathrm{kg} \mathrm{K})$ & 1305.6 \\
Specific heat of solid phase, $C_{p s},(\mathrm{~J} / \mathrm{kg} \mathrm{K})$ & 1019 \\
Latent heat of phase change, $\Delta h,(\mathrm{~J} / \mathrm{kg})$ & $2.1 \times 10^{5}$ \\
Mass diffusivity of liquid phase, $D_{l},\left(\mathrm{~m}^{2} / \mathrm{s}\right)$ & $4.75 \times 10^{-9}$ \\
Mass diffusivity of solid phase, $D_{s},\left(\mathrm{~m}^{2} / \mathrm{s}\right)$ & $7.61 \times 10^{-13}$ \\
Partition Coefficient, $\kappa$, & 0.129 \\
Eutectic temperature, $T_{e},\left({ }^{\circ} \mathrm{C}\right)$ & 577 \\
Eutectic species concentration, $C_{e},(\mathrm{wt} \%)$ & 30.6 \\
Melting temperature $T_{m},\left({ }^{\circ} \mathrm{C}\right)$ & 591 \\
\hline System data & \\
\hline Ingot dimensions, $(\mathrm{mm})$ & $80 \times 40 \times 20$ \\
Mould material, & $\mathrm{Fe}-1.5 \% \mathrm{C}$ \\
Thermal conductivity of mould material, $(\mathrm{W} / \mathrm{m} \mathrm{K})$ & 36.3 \\
Thermal conductivity of copper cooling tubes, $(\mathrm{W} / \mathrm{m} \mathrm{K})$ & 401 \\
Cooling temperature of water flow, $\left({ }^{\circ} \mathrm{C}\right)$ & 25 \\
Cooling water flow rate per unit ingot circumference, $\left(\mathrm{m}^{2} / \mathrm{h}\right)$ & 0.015 \\
\hline
\end{tabular}

\subsection{Numerical Procedures}

The present model was implemented in the fully implicit solution procedure using simpler method developed in Reference (Patanker \& Suhas, 1980) a fixed grid and a single 2-D domain shown in Figure 6(a). Figure 6(b) illustrates the control volume used in the present numerical simulation. Detailed explanations of simpler method described in the same reference. A non-uniform grid system with $80 \times 40 \mathrm{~mm}$ was adopted and the domain comes into 28 nodes. The dimension of control element in the direction of $z$ is $\Delta z=10 \mathrm{~mm}$ for all grid mash of computations as shown in Figure 6(a) whereas the dimension in direction of $x$ is $\Delta x=5 \mathrm{~mm}$ for first $20 \mathrm{~mm}$ from the ingot surface. Then, the dimension in direction of $x$ changes and becomes $\Delta x=20 \mathrm{~mm}$ for rest of ingot length.

Only steady-state solution is of interest in this study and was approached using time steps of 1 second $\Delta t=1 \mathrm{~s}$. The simulations took about 500 seconds on the average to reach steady state.

\section{Experimental and Simaulation Results, Comparisons and Analysis}

To check the validity of the model, the comparisons between simulated and measured results of the temperature distributions and silicon the segregation ratios are compared by different ways. The direct comparison of absolute values of simulated and measured temperature distributions is used as shown in Figures 7(a-d) whereas the relative average errors for macro-segregation of silicon is used as illustrated in Figures 8(a-c) and the given Equation (1) was used in these computations;

$$
\text { Error }=\frac{S_{j_{m}}-S_{j_{p}}}{S_{j_{m}}} \times 100
$$


Figurers 7(a-d) show a comparison between the measured and predicted temperatures for E1 and E2, see Table 2, at positions 3 and 4, see Figure 6. The measurements and predictions are in good qualitative agreement. The difference between the calculations results and measurements are within $\pm 12{ }^{\circ} \mathrm{C}$ where the calculated values are higher than measurements at positions 3 and 4 for E1 and E2 in certain region of the liquid and mushy zones. This difference starts to decrease in the mushy zone for position 3 whereas position 4 appears to increase in this difference in the same zone as seen in Figures 7(a-d). This is due to unstable solute gradients which are leading to additional convection component. The additional convection caused by these instabilities transports the free crystals into the hot liquid regions where they probably remelt or not. However, in the mushy zone, this type of convection may change the enthalpies in the interdendritic melt (Poirier \& Nandapurkar, 1988).

As a deep mushy zone develops the amount of free crystals transport and crystal destruction decreases. Since less nucleated free crystals are now present and in competition with each other in the liquid zone the resulting that this difference decreases. It is obvious that the measurements show the clear difference compared to the calculations in the mushy zone especially at position 4 for E1 close to solidus isotherm as shown in Figure 7(a). This is because of the continuous change in the enthalpy of interdendritic liquid within this control volume. This is due to the effect of macro-segregation of Si crystals which results in floating and concentration them in the certain locations. However, this is probably due to the complexity of heat transfer conditions when air gap forms between the ingot and steel chill and its dynamics start to be significant.

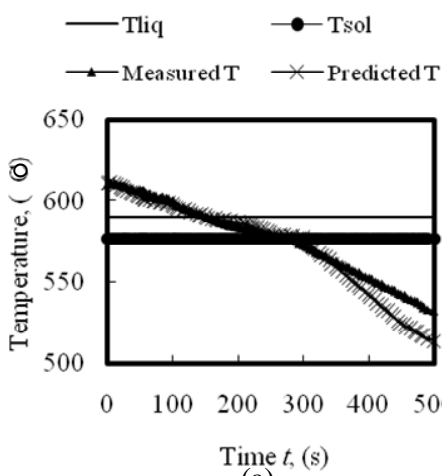

(a)

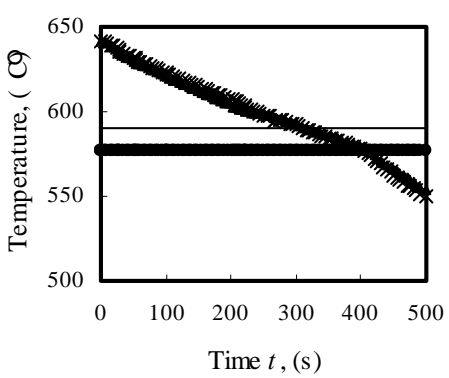

(c)

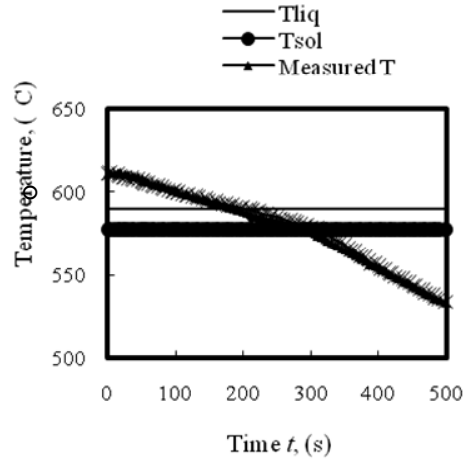

(b)

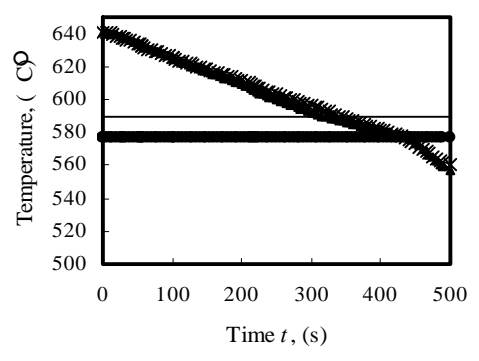

(d)

Figure 7. Comparison between experimental and simulated cooling curves at a), b) superheat $20^{\circ} \mathrm{C}, \mathrm{c}$ ) and d) superheat $50{ }^{\circ} \mathrm{C}$ at positions, 3 and 4

These simulations use different average densities with various superheats where the micro-examinations of sectioned samples reveal dendritic equiaxed structure for all the ingots as shown in Figure 3(b). These average grain densities within each control volume were calculated directly from the grain size measurements shown in Figures 5(a-c). The grain densities calculated by Equation (T-4-2) and used in Equation (T-4-1) are inversely related to grain sizes shown in Figures 5(a-c) which in turn affect primarily the permeability of flow through the mushy zone. Figures 8(a-c) show segregation errors of silicon in cast ingots for superheats 20, 50 and $75 \mathrm{~K}$, respectively. These results point out a reasonable agreement where the errors fluctuate based on the location of examined element. Note that this inaccuracy is severe in low superheat ingot $(\Delta \mathrm{T}=20 \mathrm{~K})$ whereas the inaccuracy decreases slightly with 50 and $75 \mathrm{~K}$ superheats. This is because the natural of convection stream 
velocities, their magnitudes and directions as well as the difference between aluminium and silicon densities is very small (El-Bealy \& El-Emairy, 2007; El-Bealy \& Hammouda, 2007; El-Bealy, 2010). This helps the convection streams to float the silicon crystals easily by different patterns based on the melt superheat and power chilling which control the surface heat flux and therefore the temperature gradients in the solid shell and mushy zone (El-Bealy, 1990). Also, this fluctuation is probably due to the lag in mushy permeability relations for different element locations and in the thermo-physical properties of aluminium alloys. This draws us to the needs of accurate mushy relations and properties functions based on temperature and concentration. In the next sections, it can be seen that the effects of different superheats, convection stream patterns, isotherms, movement of silicon crystals on the macro-segregation distributions will be analysed and discussed in the following sections.

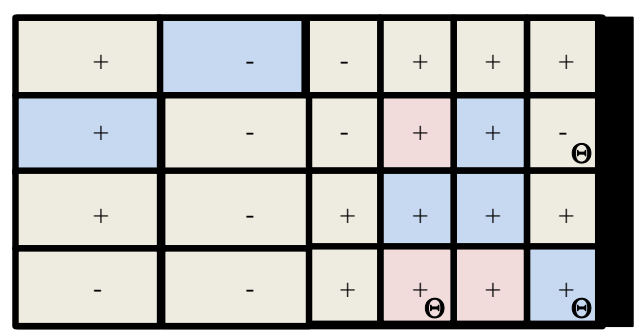

(a)

$\Delta \mathrm{T}=20 \mathrm{~K}$
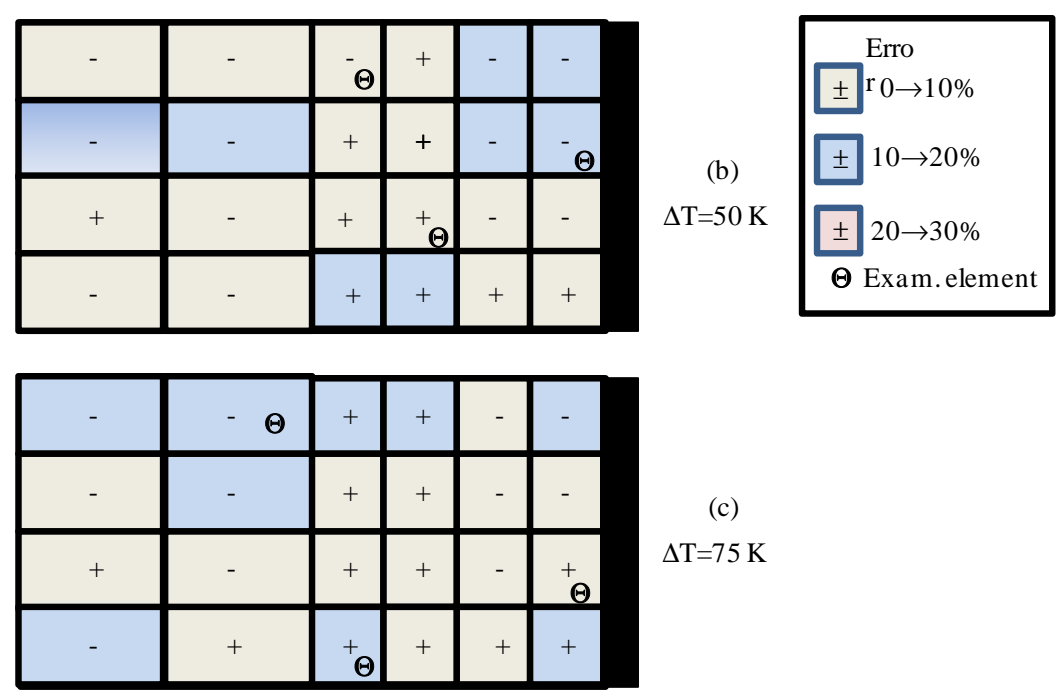

(c)

$\Delta \mathrm{T}=75 \mathrm{~K}$

Figure 8. Variation of segregation errors of examined elements with superheats a) $20^{\circ} \mathrm{C}$, b) $50{ }^{\circ} \mathrm{C}$ and c) $75{ }^{\circ} \mathrm{C}$

\subsection{Case 1}

The fluid velocity patterns and relative velocity vectors $\left(V_{l}-V_{S}\right)$ for melt superheat $20{ }^{\circ} \mathrm{C}$ is represented in Figures 9(a, b) at different times $115 \mathrm{~s}$ and $165 \mathrm{~s}$, respectively where the magnitude of average grain density is $3.3 \times 10^{9}$ $\mathrm{m}^{-3}$ in this case.

At an early stage of solidification at $t=115 \mathrm{~s}$, the liquid and interdendritic liquid flows consist of a single counter clockwise rotating convection cell as shown in Figure 9(a). This thermal-solutal convection flow does not only control the movements of liquid and solid but these movements control also by the sedimentation or floating of the free silicon crystals as shown in Figures 9(c, d) (column-1/Bottom-1) and (column-1/bottom-3) examined control elements, respectively, see Figure 8(a). The flow pattern shown in Figure 9(a) adjacent to the hot wall draws the free silicon crystals to solidify at the ingot surface by different distributed levels as shown in Figure 9(c, d). This is due to the element position and flow direction where the higher density of solid silicon crystals than the liquid which exerts a large interfacial drag on the interdendritic liquid and pulls this liquid carrying the silicon crystals to ingot surface. This sedimentation or floating driven liquid flow further augments the thermal and solutal buoyancy forces in the interdendritic liquid. Also, the permeability is different based on the position of examined element and affects the distribution of silicon crystals as shown in Firgures 9(c, d). 
The pattern of relative velocities shown in Figure 9(a) is mostly similar to the pattern of liquid and interdendritic liquid flow. The figure also shows that the magnitudes of relative velocities are smaller than the one of the liquid. This is a direct evidence of crystal sedimentation in Figure 9(c) and crystal floating in Figure 9(d).

At $t=165 \mathrm{~s}$, simulations results of an intermediate stage of solidification are shown in Figure 9(b) This figure shows that both the direction of convection stream and the relative velocities are generally similar as the pattern of early stage of solidification discussed above in this section but there is a small difference in their magnitudes. Figure 9(e) shows also the effect of direction and magnitude of different convection flows on the silicon crystal sedimentation of examined element (column-3/bottom-1), illustrated in Figure 8(a). Also, the model predictions illustrate that the width of mushy zone extends. Therefore, the convection associated with low superheat is weakened and the liquidus isotherm remains somewhat not straight partiality where the slop of this isotherm increases slightly in ingot bottom as shown in Figure 9(b). This is due to the fact that heat transfers from the upper part of the ingot into its bottom. In general, the comparisons between the measured values of isotherms from cooling curves and their predictions are in a good agreement as shown in Figures 9(a, b) at different locations from chill.

Therefore, the segregation morphologies shown in Figures 9(c-e) reveal considerable fluctuation of segregation distributions. The surface and subsurface areas of the ingot is more positively segregation. This is due to the advection of solute-rich liquid into these areas. Another striking pattern of positive segregation is at the ingot bottom. This is caused by deposition of solute-rich liquid at the ingot bottom. This is due to a bending towards the liquid isotherm of ingot bottom where the solidification is faster at the bottom than the upper part of the ingot. Another interesting observation arises from the examination of micrographs 9(c, e), where these figures show that the silicon crystals in micrograph 9 (e) is coarser than those in micrograph 9(c). This is due to the growth mechanism associated with significant difference in the cooling rates.

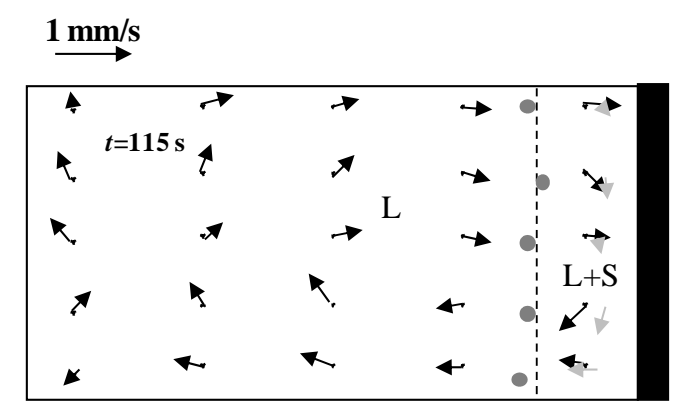

(a)
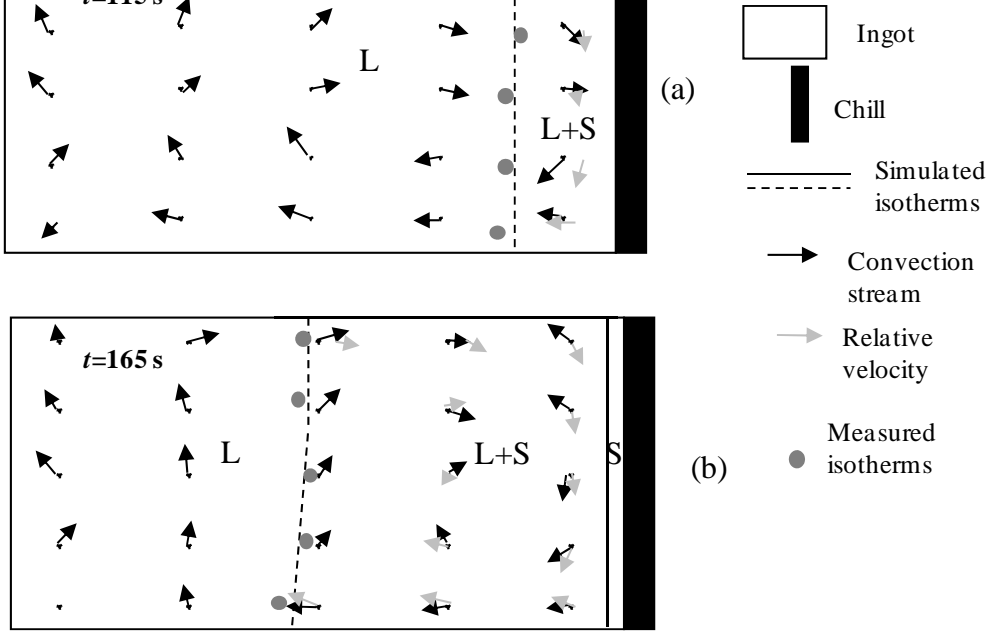

(b)

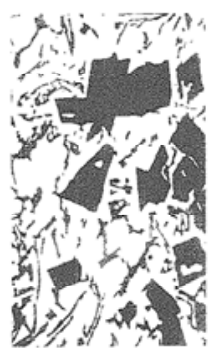

(e)

(c)

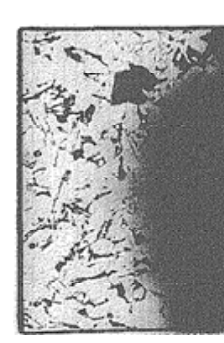

(d)

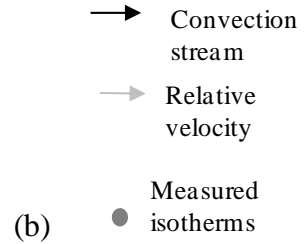

Figure 9. Showing a), b) the convection stream patterns and the relative velocities, micrographs of c) column-1/Bottom-1, d) column-1/bottom-3 and e) column-3/bottom- 1 examined elements $\times$ magnification 100 with superheat $20^{\circ} \mathrm{C}$ 


\subsection{Case 2}

In the case of ingot solidifies with $50{ }^{\circ} \mathrm{C}$ superheat shown in Figures 10(a-e), the average magnitude of grain density in this case is $4.4 \times 10^{9} \mathrm{~m}^{-3}$ and this magnitude is higher than in case 1 . Consequently, the mushy zone is relatively less permeable in this case and thermo-solutal convection can be expected to be weaker. Also, this convection stream may be higher in liquid zone than in case 1 due to the high superheat (El-Bealy \& Hammouda, 2007; El-Bealy, 2013).

The liquid velocity and relative velocity fields shown in Figure 10(a, b) at 330 and 340 s, respectively are quite similar to those in case I where the same velocity scale as in figures 10(a, b) is used. Due to high velocities in the liquid zone associated with higher superheat, the liquid velocity helps the silicon crystals to float with strong convection streams into the hotter regions in the liquid zone. Subsequently, there is no sedimentation of silicon crystals at ingot surface as shown in Figure 10(c) of examined element (column-1/bottom-3) which results in a negative surface segregation. This phenomenon decreases gradually with distance from chill as shown in Figures 10(d, e) of examined elements (column-3/bottom-2) and (column-4/bottom-4), respectively. The reason behind this phenomenon is that the mushy permeability may decrease with increasing the grain size which results in a continuous changing in the negative segregation into positive segregation in interior control elements. Another phenomenon arises from these predictions and micrographs where divergent columnar dendrites appear at the ingot surface as shown in Figure 10(c). This is due to the high surface cooling rate due to perfect contact between the ingot surface and chill. Also, this may be due to a high superheat $\left(\Delta T=50^{\circ} \mathrm{C}\right)$. However, the model predictions reveal also that the solidus isotherm is completely flat whereas the liquidus isotherm is irregular and bend toward in bottom part. This is phenomenon with the convection stream and relative velocity patterns give a clear explanation for random distributions of silicon crystals. Also, the model predictions and measured positions of isotherms show good agreements.

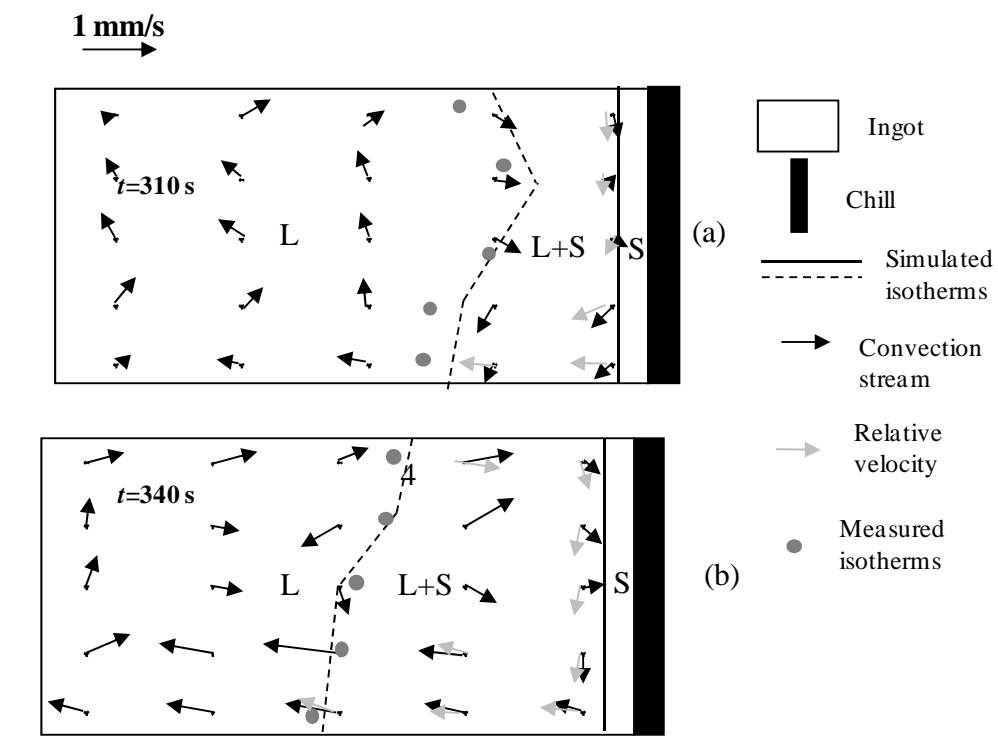

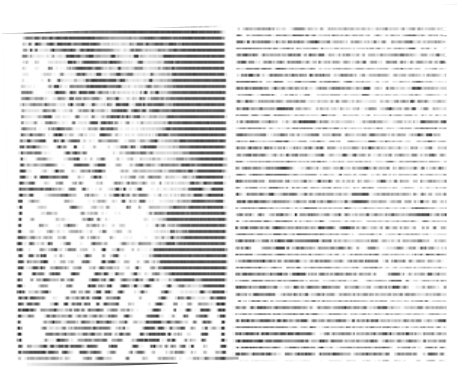

(c)

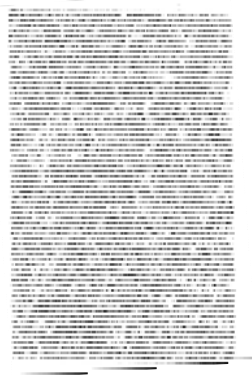

(e)

Figure 10. Showing (a), (b) the convection stream patterns and the relative velocities, micrographs of (c) column-1/Bottom-3, (d) column-3/bottom-2 and (e) column-4/bottom-4 examined elements $\times$ magnification 100 with superheat $50^{\circ} \mathrm{C}$ 


\subsection{Case 3}

This simulation plotted in Figure 11(a, b) was carried out to study the effect of convection streams and movement of solid on the macro-segregation, isotherms flatness and the movements of silicon crystals at times 315 and $375 \mathrm{~s}$, respectively with $75^{\circ} \mathrm{C}$ superheat. The average grain density of this case is $4.31 \times 10^{9} \mathrm{~m}^{-3}$.

Not surprisingly, the liquid, interdendritic liquid and relative velocities are very similar to cases 1 and 2 . The micrograph (column-1/bottom-2) examined element and demonstrated in Figure 11(c) exhibits positive surface segregation. This is due the direction and small magnitude of convection stream velocities as shown in Figure 11(a). This mechanism continues to affect the segregation as illustrated in micrograph 11(d) of (column-4/bottom-1) examined element where the convection streams are weak in the mushy zone, see Figure 11(b) and cannot carry or help to float the silicon crystals again into the liquid zone. However, morphology appeared in Figure 11(e) points out that there is a negative segregation of examined element (column-5/bottom-4). Another interesting observation arises from the examinations of morphologies illustrated in Figures 11(c-e) where the size of silicon crystals decreases with distance from chill. This phenomenon agrees well with mechanism of separation theory developed in Reference (Ohno, 1987) and observations in Reference (El-Bealy \& Hammouda, 2007) where the high rate of separated crystals from chill associated with sufficient initial convection streams in the liquid zone increases the number of separated free crystals and decreases their sizes (Ohno, 1987; El-Bealy \& Hammouda, 2007). Consequently, the crystals size in later stages of separation mechanism is coarser than those in the early stages in this mechanism which results in this phenomenon. However, the comparisons between the measured and predicted isotherms appeared in Figures 11(a,b) at various times seem good. Also, these results reveal that there is no any flatness of liquidus or solidus isotherms during different stages of ingot solidification. This depends on the heat transfer through the ingot which is based on the magnitude and direction of convection streams.

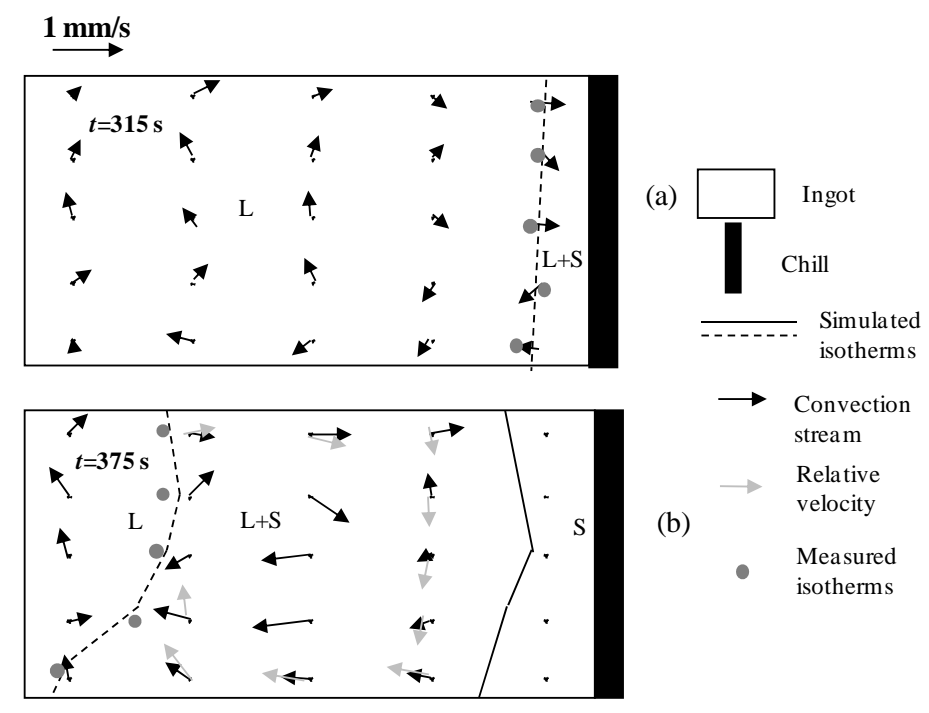

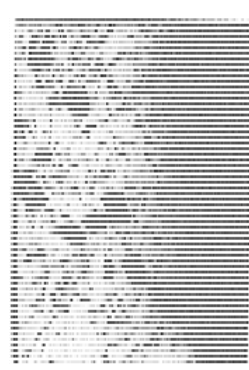

(c)

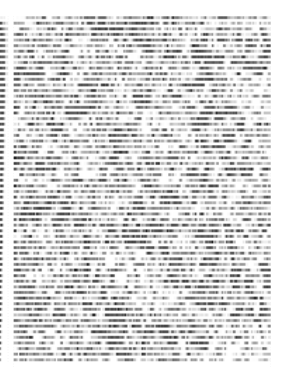

(d)

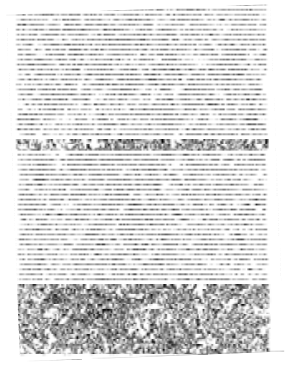

(e)

Figure 11. Showing (a), (b) the convection stream patterns and the relative velocities, micrographs of (c) column-1/Bottom-2, (d) column-4/bottom- 1 and (e) column-5/bottom- 4 examined elements $\times$ magnification 100 with superheat $75^{\circ} \mathrm{C}$ 
In general, these results give an important attention for including the effect of solid movement during the mushy zone on the predicting macro-segregation especially with alloy which has similar densities of both of aluminium and its alloying elements.

\section{General Discussion}

Over the wide range of previous investigations (El-Bealy, 1990; Griffiths et al., 1996; Wang \& Beckermann, 1996; El-Bealy \& Hammouda, 2007) and here in detail, it is shown that the natural convection streams generated in dendritic equaixed structure and resulting from the coupled effect of thermo-solute convections significantly affect the distribution of alloying elements and then the segregation distributions of these alloying elements. This is because of the complicated mechanism of convection streams which influences the mechanisms of free crystals separation, cast structure formation and its type. Also, these convection patterns affect the solid movement in liquid and mushy zones which results in the random distribution of alloying elements especially on the ingot surface areas as shown in Figures 9(c-e), 10(c-e) and 11(c-e). Also, the non-uniform heat extraction during mould cooling process associated with different mould cooling regions and air gap formation affects the convection streams and its magnitude considerably (Jackson \& Hunt, 1966; Hansen et al., 1996; El-Bealy, 2013).

As the initial cooling starts on the mould wall with low heat transfer coefficients for different superheats, it is considered that the crystal separation theory is a controlled the solidification process (Ohno, 1987). The growth of the root of crystals nucleated on the mould wall is being restrained by the liquid with low melting point composition. They grow into a top heavy shape and when such necked-shape crystals are formed on the mould wall, their roots are instable and convection easily causes them to separate. Even without significant convection streams, the difference between the specific gravity of the crystallized crystals and that of the molten metal is large. Therefore, the small neck cannot support the big heat and even a slight movement of the molten metal causes the crystals to separate from the mould wall. The separated crystals then induce nearly crystals to separate. When the crystals that have separated from the mould wall are extremely light in the comparison to the molten metal, they float up against the downwards convection along the mould wall. If they are heavier than the molten metal they precipitate along the mould wall. Based on the convergence in the magnitudes of temperature gradients in $x$ and $z$ directions, the possibility of equiaxed structure formation increases. When the temperature of chill wall crystals reaches the coherence temperature, the fine equiaxed chill zone starts to form. The equiaxed crystals start to grow divergently and form a thin coherent shell at the ingot surface. This thin shell shrinks and the air gap begins to form. The width of the air gap and its growth rate are based on the surface cooling rate and solidificaton behaviour of alloy. Then, the air gap width increases and therefore heat transfer coefficient begins to decrease steeply within very small period time. The free crystals float up against the downwards convection streams and the mushy zone starts to shape forming the isotherms, see Figures 9 (a, b), 10(a, b) 11(a, b). The grain size of equaixed crystals is controlled by the number of separated free crystals (El-Bealy \& Hammouda, 2007). Consequently, the number of grains and its size begin to affect the mushy permeability (Beckermann \& Viskanta, 1993; Reddy \& Beckermann, 1997; El-Bealy, 2013). This affects the interdendritic fluid flow between the equiaxed crystals and therefore influences the surface macro-segregation levels. In addition to the grain size and its mushy permeability, the movement of silicon crystals adds another factor to distribute these silicon crystals randomly as shown in Figures 9(c, d), 10(c) and 11(c).

As the solidification continuous and the mushy zone become deep, heat transfer coefficient begins to decease slowly and gradually. The grain multiplication is an important nucleation mechanism and general source of crystals in castings and ingots without changing in the thermal fields or temperature gradients. Apparently, the grain multiplication is caused by different ways when crystals separate from the mould and move into a high temperature region in the liquid zone. They melt from outside and when they enter into a low temperature region they grow again. If the crystals have necked-shape branches, new crystals are born through the partial remelting and separation of the branches. This crystals multiplication does not occur only as a result of heterogeneity in the temperature of the molten metal in the mould but also occurs through heterogeneity in the concentration of the solute. For these reasons, it is expected that thermal field and its convection pattern are play an important role to form the cast structure and control its type in the ingot interior. Also, the separation of the branches affects the mushy permeability and increases the possibility to resist the interdendritic flow randomly. Due to wide mushy zone, the silicon crystals float with convection streams and distribute randomly as shown in Figures 9(b), 10(b) and 11(b). These crystals participate randomly in the control volumes of ingot interior and take the same patterns and directions of convection streams. Evidence of these conclusions, it can be seen in the micrographs 9(e), 10(d, e) and 11(d, e). 
In the light of these facts, these results and their conclusions may be explained the complicated mechanisms of formation of dendritic solidification defects such as extruded surface segregation layer and interdendritic longitudinal mid-face crack.

In the case of extruded surface segregation layer, micrographs 12(a, b) reveal the extruded surface segregation layer of AA-6061 and AA-1050 alloys, respectively (El-Bealy, 2010, 2012). These micrographs show that surface segregation of AA-6061 alloy is higher than in the case of AA-1050 alloy where the alloy composition plays a major role in this defect. It is well known that the movement of interdendritic rich solute liquid controlled mainly by thermo-metallurgical strains and mushy permeability. Also, this movement controls the macro-segregation formation and its levels (El-Bealy \& Fredriksson, 1996; El-Bealy, 2010, 2012). In the case of AA-6061 alloy, the segregation of magnesium and increases its concentration continuously during solidification $\left(\mathrm{Mg}_{0}=0.8 \% \mathrm{Mg}\right)$ decreases the density of interdendritic liquid which increases the effect of any slight thermo-metallurgical strain on the movement of interdendritic liquid. This forces easily the interdedritic solute rich liquid into ingot surface and fills the space of air gap as shown in Figure 12(a). However, the segregations of silicon $\left(\mathrm{Si}_{0}=0.25 \% \mathrm{Si}\right)$ and iron $\left(\mathrm{Fe}_{0}=0.4 \% \mathrm{Fe}\right)$ in the case of 1050 alloy affect the mushy permeability by two different ways. The segregation of silicon forces the silicon crystals to float in the interdendritic liquid and from an additional resistance for this flow whereas in the case of iron, iron segregation increases the density of interdendritic liquid and makes the movement of the interdendritic fluid to the ingot surface more difficult. Therefore, it cannot fill completely the space of air gap formed between between the mould wall and ingot surface as shown in Figure 12(b) (El-Bealy, 2010, 2012).

However, graphs 12(c, d) illustrate the interdendritic longitudinal mid-side face cracks of low carbon and peritectic steels, respectively (Ali, 2012). These graphs exhibit that the crack changes its natural location on the slab broad face from mid-face $\left(\mathrm{Si}_{0}=0.34 \% \mathrm{Si}\right)$ into the side-face close the narrow face of the slab $\left(\mathrm{Si}_{0}=0.40 \%\right.$ Si) as seen in Figures 12(c, d), respectively, (Ali, 2012). This may be due to an inhomogeneity distribution of silicon crystals on the slab surface associated with the movements of these crystals due to different turbulent flow patterns. This may distribute the silicon crystals randomly and may form different silicon segregations on the different slab surface areas. This increases or decreases the partition coefficient of carbon which affects the carbon segregation level (El-Bealy, 1995). This increases or decreases the occurrence of this type of cracks and defines its location based on the surface cooling rate and partition of coefficient of carbon in multi-component systems (El-Bealy, 2001). 


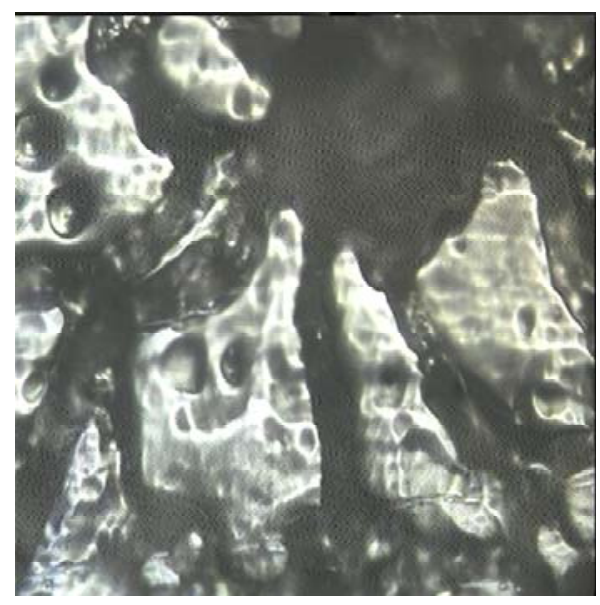

(a)

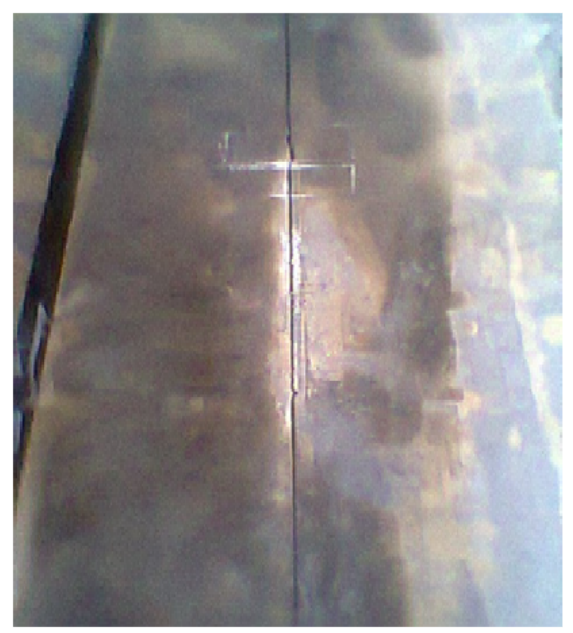

(c)

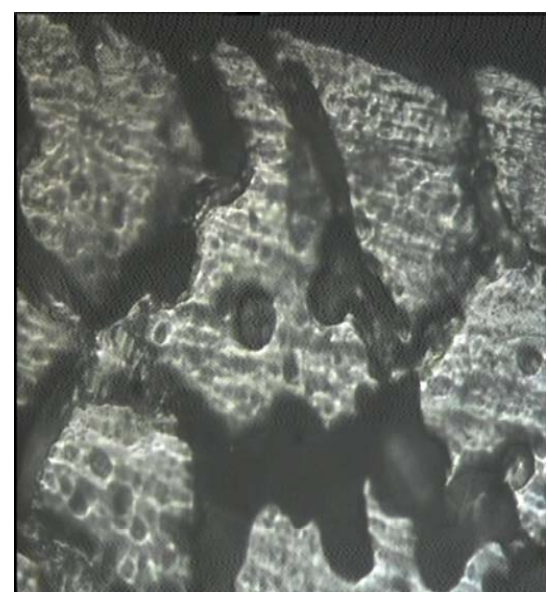

(b)

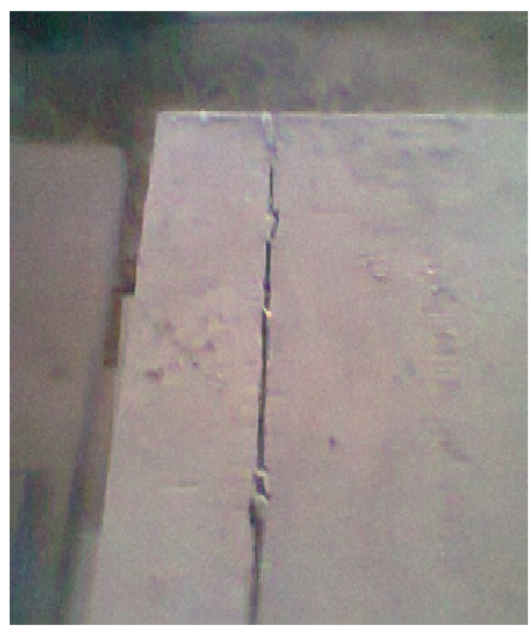

(d)

Figure 12. a) Photomicrographs of Extruded surface segregation layer of AA-6061 aluminum alloy with 400 times magnification and photographs of interdendritic longitudinal b) mid-face and c) side-face surface cracks

\section{Concluding Remarks}

The aim of this paper is to describe experimentally and theoretically the effects of different melt superheats of end chill ingots on the natural convection streams, the movements of interdendritic liquid, silicon crystals and therefore on the macro-segregation distributions. The primary purpose of mathematical model is to compute a 2-D thermal and natural convection fields, as well as the movements of interdendritic liquid and solid phases within the mushy zone. Also, the model employs to simulate the isotherms shapes and macro-segregation of silicon where the computed results are in the reasonable agreements with measurements and experimental observations.

Computed results have revealed that the natural convection streams have noteworthy effect on the thermal fields within especial parts in the liquid and mushy zones. The direction of convection stream patterns is clockwise at one cell in liquid zone at different superheats where the liquid transports from the hot region to the cold one due to the heat transfer. The magnitude of convection velocity stream is higher in case of higher superheat in different phases whereas its magnitude in the bottom of mould cavity is higher than its magnitude in the top part. The convection streams influence the isotherms. Also, the superheat of melt plays a major role to control the flatness and shape of isotherms. This flatness is higher with low superheat and visa versa. Also, the convection streams result in a high fluctuation in macro-segregation distributions due to a separation and movement of silicon crystals randomly. Subsequently, in the case of positive or negative small difference between the aluminium and alloying element densities such as silicon, the movement of solid phase affects significantly the macro-segregation and it should be taken into the considerations of macro-segregation simulation. 
Although the model predictions are generally supported by the present and previous published experimental results, it is necessary to create more investigations by both experimental and numerical modelling to refine the model and solve the remaining problems. Another important aspect of the future work is to explain accurately some of complicated mechanisms of dendritic solidification defects during initial stages of solidification processes and therefore design a suitable mould system to control and avoid the surface defects such as high extruded surface segregation layer and interdendritic longitudinal mid-side face surface cracks. In this future work, we may study deeply the parameters affected the formation stages of cast structure and casting defects.

\section{Acknowledgements}

The author wishes to express his sincere gratitude to Prof. Merton Flemings, Massachusetts Institute of Technology (MIT), former Head of Department of Materials Science and Engineering, Massachusetts, USA for his early pioneer work in the segregation fields which guides the author to several facts in these fields. The author also wishes to express his sincere gratitude to Prof. Hasse Fredriksson, Royal Institute of Technology, Dept. of Materials Science and engineering, Div. of Casting of Metals, Stockholm, Sweden for his considerable supervision, guidance, helpful discussions throughout the work and valuable assistance in macrosegregation field since 1995. Also, his sincere gratitude is due to the assistances and technicians at the metallurgical laboratory and workshops of Faculty of engineering, Ain Shams University. The author's sincere gratitude is due to Prof. Dr. Eng. W. Reif, former head of "Institut fur Metallforschung Fachgebiet Metallkunde”, TU-Berlin, Germany and to the assistances and technicians at the institute. This program was financed by German Academic Exchange Service "DAAD” which is also acknowledged.

\section{References}

Agarwal, P. K. (1988). Transport phenomena in multi-particle systems-II. Particle-fluid heat and mass transfer. Chem. Eng. Sci., 43, 2501-2510. Retrieved from http://www.mendeley.com/research/transport-phenomena-multi-particle-systems-ii-particle-fluid-heat-mass -transfer/\#

Ali, I. S. (2012). On the Formation of Longitudinal Mid-Side/Face Interdendritic Surface Cracks in Continuously Cast Steel Slabs. Technical communications, Egyptian Iron and Steel Company, El-Tabien, Helwan, Egypt.

ASTM Grain size. (1987). Planimetric Method. Metallography, 35, 18-19.

Bamberger, M., Weiss, B. Z., \& Stupel, M. M. (1987). Heat flow and dendritic arm spacing in chill-cast Al-Si alloys. Mater. Sci. Technol, 3, 49-56. http://dx.doi.org/10.1179/026708387790123070

Beckermann, C. \& Viskanta, R. (1993). Mathematical modeling of transport phenomena during alloy solidification. Appl. Mech. Rev., 46, 1-27. http://dx.doi.org/10.1115/1.3120318

De Groh III, H. C. (1994). Undercooling-Induced macrosegregation in directional solidification. Metall. Trans. A., 25A, 2507-2516. http://dx.doi.org/10.1007/BF02648870

DeHoff, R. T., \& Rhines, F. N. (1968). Quantitative Microscopy (1st ed.). Materials Science and Engineering Series, New York, NY: McGraw-Hill. Retrieved from http://books.google.com.eg/books/about/Quantitative_microscopy.html?id=QYZQAAAAMAAJ\&redir_esc $=\mathrm{y}$

El-Bealy, M. (1995). On The Mechanism of Halfway Cracks and Macrosegregation of Continuously Cast Steel Slabs, Part II: Macrosegregation. Scandinavian J. of Metallurgy, 24, 106-20.

El-Bealy, M. (2000). Modeling of interdendritic strain and macrosegregation for dendritic solidification processes: Part II. Computation of interdendritic strain and segregation fields in steel ingots. Metall. Trans., B, 31B, Part I \& II, 331-343, 345-355. http://dx.doi.org/10.1007/s11663-000-0053-8

El-Bealy, M. O. (1990). Numerical Simulation of Solidification in Simple Shaped Castings (Master Thesis, Ain Shams University, Faculty of Engineering, Cairo, Egypt).

El-Bealy, M. O. (2001). Modeling of interdendritic strain and interdendritic cracking phenomena during dendritic solidification processes. In Proceed. of TMS Conference, San Diego, CA, USA, 683-692. Retrieved from http://iweb.tms.org/Purchase/ProductDetail.aspx?Product_code=01-5131-683

El-Bealy, M. O. (2010). On the Formation of Interdendritic Crack in Equaxied Crystal Structure During Aluminum Direct Chill Casting Process. In M. Cross., J. W. Evans, \& C. Bailey (Ed.), Light Metals (pp. 683-88), Warrendale, PA, USA: TMS-AIME. 
El-Bealy, M. O. (2011). A mathematical model of interdendritic thermometallurgical strain for dendritic solidification processes. Metall. Trans. B., 42B, 1280-1296. http://dx.doi.org/10.1007/s11663-010-9464-3

El-Bealy, M. O. (2012). Influence of casting direct chill casting process variables on surface quality of aluminum alloy sheet ingots. In Proceed. Of Light Metals, TMS-Annual meeting "Cast Shop Technology”, Orlando, Florida, USA, 1107-1112.

El-Bealy, M. O. (2013). Advanced Solute Conservation Equations for Dendritic Solidification Processes, Part I \& II. Manuscript submitted for publication.

El-Bealy, M. O., \& El-Emairy, H. A. (2007). Natural Convection Streams and Equiaxed Crystals During Dendritic Solidification Processes. In Proceed. Of "Light Metals" TMS-Annual Meeting "Cast Shop Technology", Orlando, FL, USA, 765-74.

El-Bealy, M. O., \& Hammouda, R. M. (2007). On the mechanism of natural convection and equiaxed structure during dendritic solidification processes. Steel Research International, 78, 602-11. http://dx.doi.org/10.2374/SRI06SP128-78-2007-602

El-Bealy, M. O. (2010). On the Formation of extruded surface segregation layer in aluminum direct chill casting process. $\quad$ Can. Metall. Q., 49, 47-62. Retrieved from http://www.ingentaconnect.com/content/maney/cmq/2010/00000049/00000001/art00006

El-Bealy, M., \& Fredriksson, H. (1996). Modeling of the peritectic reaction and macro-segregation in casting of low carbon steel. Metall. Trans. B., 27B, 999-1014. http://dx.doi.org/10.1007/s11663-996-0015-x

Geiger, G. H., \& Poirier, D. R. (Eds.) (1973). Transport Phenomena in Metallurgy (92). MA: Addision-Wesley Publishing Company, Reading.

Griffiths, W. D., Xiao, L., \& McCartney, D. G. (1996). The influence bulk liquid natural-convection on the formation of the equiaxed regions in Al-Cu and Al-Si alloys. Mater. Sci. Eng., 205A, 31-39. Retrieved form http://serials.unibo.it/cgi-ser/start/it/spogli/ds-s.tcl?authors=\%22GRIFFITHS+WD\%22\&language=ITALIA $\mathrm{NO}$

Hansen, G., Hellawell, A., Lu, S. Z., \& Steube, R. S. (1996). Some Consequences of thermosolutal convection: the grain structure of castings. Metall. Trans. A., 27A, 569-581. http://dx.doi.org/10.1007/BF02648947

Ho, K., \& Pehlke, R. D. (1985). Experimental Determination of Heat Transfer Within the Metal/Mold Gap in a DC Casting Mold: Part II. Effect of Casting Metal, Mold Material, and Other Casting Parameters. Metall. Trans. B., 16B, 585-94. http://dx.doi.org/10.1007/s11661-013-1646-6

Jackson, K. A., \& Hunt, J. D. (1966). Lamellar and Rod Eutectic Growth. Trans. Of Metallurgical Society of AIME, 236, 1129-1142.

Korojy, B. (2009). Volume Change effects during Solidification of alloys (PhD Thesis, Royal Institute of Technology, Stockholm, Sweden).

Kristiansson, J. O. (1982). Thermal stresses in the early stage of solidification of steel. J. Thermal Stresses, 5, 315-30. http://dx.doi.org/10.1080/01495738208942153

Mangnusson, T., \& Arnberg, L. (2001). Density and solidification shrinkage of hypoeutectic aluminum-silicon alloys. Metall. Trans. A., 32A, 2605-2613. http://dx.doi.org/10.1007/s11661-001-0050-9

Muller, G., Neumann, G., \& Weber, W. (1984). Natural convection in vertical Bridgman configurations. J. of Crystal Growth, 70, 78-93. http://dx.doi.org/10.1016/0022-0248(84)90250-1

$\mathrm{Ni}$, J., \& Beckermann, C. (1991). A volume-averaged two-phase model for transport phenomena during solidification. Metall Trans. B., 22B, 349-61. http://dx.doi.org/10.1007/BF02651234

Ni, J., \& Beckermann, C. (1993). Modeling of Globulitic Alloy Solidification with Convection. J. Mater. Processing Manufacturing Sci., 2, 217-31. Retrieved from http://www.engineering.uiowa.edu/ becker/publ.html

Nielsen, O., Arnberg, L., Mo, A., \& Thevik, H. (1999). Experimental determination of mushy zone permeability in aluminum-copper alloys with equiaxed microstructures. Metall. Trans. A., 30A, 2455-2462. http://dx.doi.org/10.1007/s11661-999-0254-y

Ohno, A. (1987). Solidification. Berlin, Heidelberg, New York: Springer-Verlag. http://dx.doi.org/10.1007/978-3-642-95537-2 
Patanker, S. V., \& Suhas, V. (1980). Numerical Heat Transfer and Fluid flow. New York: Hemisphere Publication Corporation.

Poirier, D. R., \& Nandapurkar, P. J. (1988). Enthalpies of a binary alloy during solidification. Metall. Trans. A., 19A, 3057-3061. http://dx.doi.org/10.1007/BF02647732

Poirier, D. R., Nandapurkar, P. J., \& Ganesan S. (1991). The energy and solute conservation equations for dendritic solidification. Metall. Trans. B., 22B, 889-900. http://dx.doi.org/10.1007/BF02651165

Reddy, A. V., \& Beckermann, C. (1997). Modeling of macrosegregation due to thermosolutal convection and contraction-driven flow in direct chill continuous casting of an Al-Cu round ingot. Metall. Trans. B, 28B, 479-89. http://dx.doi.org/10.1007/BF02651165

Rowe, P. N., Nienow, A. W., \& Agbim, A. J. (1972). Mixing and segregation characteristics of binary granular material in tapered fluidized bed: a CFD study. Trans. Inst. Chem., Eng., 50, 324-331. http://dx.doi.org/10.4236/eng.2012.44029

Scheil, E. (1947). Metallforschung, 2, 69.

Shah, N. A., \& Moore, J. J. (1989). Effect of thermal conditions and alloying constituents (Ni, Cr) on macrosegregation in continuously cast high-carbon (0.8 Pct), low-alloy steel. Metall. Trans. B., 1989, 20B, 893-910. http://dx.doi.org/10.1007/BF02670195

Stangeland, A., Mo, A., Nillsen, $\phi .$, Eskin, D., \& M'hamdi, M., (2004). Development of thermal strain in the coherent mushy zone during solidification of aluminum alloys. Metall. Trans. A., 35A, 2903-2915. http://dx.doi.org/10.1007/s11661-004-0238-x

Sully, L. D. J. (1976). The thermal interface between castings and chill molds. AFS Trans., 84, 735-44. Retrieved from http://scholar.google.com.eg/scholar?q=related:161hAZnyVO8J:scholar.google.com/\&hl=en\&as_sdt=0,5

Wang, C. Y., Ahuja, S., Beckermann, C., \& De Groh III, H. C. (1995). Multiparticle interfacial drag in equiaxed solidification. Metall. Trans. B., 26B, 111-19. http://dx.doi.org/10.1007/BF02648984

Wang, C. Y., \& Beckermann, C. (1996). Equiaxed dendritic solidification with convection: Part I. Multiscale/multiphase modeling. Metall. Trans. A, 27A, 2754-64. http://dx.doi.org/10.1007/BF02652369

Weiner, J. H., \& Boley, B. A. J. (1963). Elasto-plastic thermal stresses in a solidifying body. Mech. Phys. Solids, 11, 145-54. http://dx.doi.org/10.1016/0022-5096(63)90049-8 